http://jmscr.igmpublication.org/home/ ISSN (e)-2347-176x ISSN (p) 2455-0450

crossref DOI: https://dx.doi.org/10.18535/jmscr/v8i12.38

\author{
(D) Journal Of Medical Science And Clinical Research \\ IGM Publication \\ An Official Publication of IGM Publication
}

\title{
Physiology of Pain a Review
}

\author{
Author \\ Dr A.B. Solepure \\ Dean IIMSR Medical College \\ Corresponding Author \\ Dr A.B. Solepure
}

\begin{abstract}
Pain is an unpleasant experience that results from both physical and psychological responses to injury. A complex set of pathways transmits pain messages from the periphery to the central nervous system, where control occurs from higher centres. Primary afferent pain fibres synapse with second-order neurons in the dorsal horn of the spinal cord. Ascending spinothalamic and spinoreticular tracts convey pain up to the brain, where pain signals are processed by the thalamus and sent to the cortex. Descending tracts, via the midbrain periaquaductal grey and nucleus raphe magnus, have a role in pain modulation. When nerves are damaged, neuropathic pain results and various mechanisms have been proposed for how this takes place. These mechanisms involve both peripheral and central sensitization. inthis study we tried to focus on the various types of pain, pain receptors and their stimulation causes of pain the main aspects of our article specifies Surgical interruption of pain pathways and Special Capability of pain signals to arouse overall brain excitability, Brain opiate system Gate control theory of pain suppression and Localization of referred pain transmitted via the visceral pathway.

Conclusion: The neurobiology of pain is continuously being explored and the novel therapeutic targets for pain relief are being tested. The multiple complex circuitries of the pain pathway, with central and peripheral modulation of the perception, make it a very complex sensation with sensory, cognitive and emotional components associated with it. This article gives a broad overview of the physiology of pain. It explains pain as a complex experience involving both physical and psychological adaptations. The normal pain pathways are described in some detail in a systematic fashion from nociceptor to central nervous system and back to periphery

Keywords: Central sensitization; gate-control theory; neuropathic pain; nociception; pain pathways; peripheral sensitization; somatic pain; visceral pain.
\end{abstract}

\section{Introduction}

Nociceptor is discovered by Charles Scott Sherrington in 1906.Nociceptor is a high threshold sensory receptor that is capable of transducing noxious stimuli into pain. Sleeping nociceptor ${ }^{(1)}$ Some of the nociceptors do not respond to stimuli unless tissue injury has actually occurred. Pain is an unpleasant sensory and emotional experience associated with actual or potental tissue damage. It has been defined by Sherrington as "the Psychical adjunct of an imperative protective reflex $^{(2)}$. The primary response for a painful stimuli is to initiate a protective reflex and secondarily it adds Signal in consciousness. 
Person's past experience fears and anxieties play an important role in its perception. Pain is mainly protective mechanism for body. It occurs whenever any tissue is being damaged and it causes the individual to react to remove pain stimuli.

\section{Types of Pain}

Pain has been classified into two major types fast pain and slow pain. Fast pain is felt within about0.1 second after a pain stimulus is applied, whereas slow pain begins only after 1 second or more and then increases slowly over many seconds and sometimes even minutes. ${ }^{(3)}$

Fast pain is also described by many alternate names such as sharp pain, pricking pain, acute pain and electric pain. This type of pain is felt when a needle is struck into the skin, when the skin is cut with a knife, or when skin is acutely burnt. Fast sharp pain is not felt in deeper tissues of body. Slow pain also goes by multiple additional names such as, slow burning pain, aching pain, throbbing pain nauseous pain and chronic pain. ${ }^{(4)}$ This type of pain is usually associated with tissue destruction. It can lead to prolonged, unbearable suffering. ${ }^{(5)}$

\section{Pain receptors and their Stimulation}

All pain receptors are free nerve endings. The pain receptors in skin and tissues are all free nerve ending. They are widespread in superficial layers of skin as well as in certain internal tissues, such as periosteum, arterial walls, the joint surfaces, and falx and tentorium of cranial vault. Three types of stimuli excite the pain receptors:Mechanical, thermal and chemical. ${ }^{(6)}$

Fast pain is elicited by mechanical and thermal types of stimuli, whereas slow pain can be elicited by all 3 types of stimuli. Some of chemicals that excite the chemical type of pain include bradykinin, serotonin, histamine, potassium ions, acids, actyl choline and proteolytic enzymes. ${ }^{(7)}$ In addition prostaglandin and substance $P$ enhance sensitivity of pain. The chemical substances are especially important in stimulating slow, suffering type of pain that occurs after tissue injury. ${ }^{(8)}$

\section{Non-adapting nature of Pain Receptors}

The pain receptor's adapt very little and sometimes not at all. In fact under some conditions, the excitation of pain fibers becomes progressively greater especially so for slow aching nauseous pain, as the pain stimulus continues. This increase in sensitivity to pain receptor is called "hyperalgesia. ${ }^{(9)}$ The importance of this failure of pain receptors to adapt is because it allows them to keep the person apprised of a damaging stimulus that causes the pain as long as it persist.

\section{Causes of pain}

1. Rate of tissue damage due to heat, bacterial infection, tissue ischaemia, tissue contusion.

2. Tissue ischaemia: Accumulation of large amounts of lactic acid as result of anaerobic metabolism. It is also possible that other chemical agents such as bradykinin and proteolytic enzymes due to cell damage rather than lactic acid stimulate the pain nerve endings.

3. Muscle spasm as a cause of pain: This pain results partially from direct effect of muscle spasm in stimulating mechano sensitive pain receptors. Ischaemia possibly results also from indirect effect of muscle spasm to compress the blood vessels and spasm also increase rate of metabolism, creating ideal conditions for release of chemical pain inducing substance. ${ }^{(10)}$

\section{Dual transmission of pain signals into the central nervous system}

Even though all pain receptors are free nerve endings these endings use two separate pathways for transmitting pain signals into the CNS. The two pathways at least partially correspond to two types of pain, a fast sharp pain pathway and slow chronic pathway. ${ }^{(11)}$ 


\section{Peripheral pain fibers - fast and slow}

The fast sharp pain signals are elicited by either mechanical or thermal pain stimuli. They are transmitted in peripheral nerves to the spinal cord by small type A delta (Ad) fibers at velocities between 6 and $30 \mathrm{~m} / \mathrm{s}$. On the other hand the slow chronic type of pain is specifically elicited by chemical stimuli but also at times by persisting mechanical or thermal stimuli this is slow-chronic pain is transmitted by type $\mathrm{C}$ fibers at velocities of between 0.5 to $2 \mathrm{~m} / \mathrm{s} .{ }^{(12)}$ Because of this double system of pain transmission, a sudden onset of pain stimulus often gives double pain sensation. A fast - sharp pain that is transmitted to brain by A delta (Ad) fibers followed by a second or so later by a slow pain that is transmitted by $\mathrm{C}$ fiber pathway. The sharp pain apprises the person rapidly of damaging influence and therefore plays an important role in making person react immediately to remove himself or herself from stimulus. On other hand slow pain tends to become more and more painful over period of time. This sensation eventually gives one the intolerable suffering by long continued pain. ${ }^{(13)}$ On entering spinal cord from dorsal spinal roots, the pain fibers terminate on neurons in dorsal horns.

\section{Dual pathways in cord and brain Stem}

On entering the spinal cord, the pain signals take two pathways to brain through neospinothalamic tract and paleospinothalamic tract.

\section{Neospinothalamic tract for fast Pain:}

The fast type A delta (A $\delta$ ) pain fibers transmit mainly mechanical and acute thermal pain. They terminate mainly in Lamina 1 (Lamina marginalis) of dorsal horns and there excite second order neurons of neospinothalamic tract. These give rise to long fibers that cross immediately to opposite side of cord through anterior commissure and then pass upward to brain in anterolateral column. A few fiber of neospinothalamic tract terminate in reticular areas of brain stem but most pass all the way to thalamus, terminating in ventrobasal complex. ${ }^{(14)}$ From these areas the signals are transmitted to other basal areas of brain and somatic cortex. Glutamate is believed to be secreted at the A delta (A $\delta)$ type of nerve pain fiber.

\section{Paleospinothalamic pathway for transmitting slow chronic pain (Polymodal pathway)}

The paleospinothalamic pathway or poly modal pathway is much older system and transmits pain mainly through type $\mathrm{C}$ pain fibers. In this pathway the peripheral fibers terminate almost entirely in lamina II and III of dorsal horns which together are called substantia gelatinosa. Most of signals then pass through one or more additional short fiber neurons within dorsal horns themselves before entering lamina V through VIII also in dorsal horn. Here the last neuron in series give rise to long axons that mostly join the fibers from fast pathway passing first through anterior commissure to opposite side of cord and then upward to brain in same anterolateral pathway. ${ }^{(1,14)}$

The slow chronic paleospinothalamic pathway terminates widely in brain stem. One tenth to one fourth of fibers only pass all the way to thalamus remaining terminate principally in one of 3 areas.

1. Reticular nuclei of medulla, pons and mesencephalon.

2. The tectal area of mesencephalon deep in superior and inferior colliculi.

3. The periaqueductal region surrounding the aqueduct of Sylvius. These lower regions of brain appear to be important in appreciation of different type of pain. From brain stem pain areas, multiple short fiber neurons relay the pain signals upward into intralaminar and central nucleus of thalamus and into certain portions by hypothalamus and other adjacent regions of basal brain.

Type C pain nerve fiber secretes both glutamate and substance $\mathrm{P}$ transmitter. There is very poor capability of nervous system to localize precisely the source of pain transmitted in slow chronic 
pathway. ${ }^{(15)}$

Special Capability of pain signals to arouse overall brain excitability:

Electrical stimulation in reticular areas of brain stem and in the intralaminar nuclei of thalamus. The are as where slow suffering type of pain terminates has strong arousal effect on nervous activity throughout the brain. In fact these two areas constitute part of brain's principal arousal system. This explains why a person with severe pain is frequently strongly aroused and also why it is almost impossible for person to sleep when he or she is in severe pain. ${ }^{(16)}$

\section{Surgical interruption of pain pathways}

Often a person has such severe and intractable pain resulting from rapidly spreading cancer that it is necessary to relieve pain. To do this the pain nervous pathways can be destroyed at one or several points. If the pain is in lower part of body, a cordotomy in upper thoracic region of spinal cord often relieves the pain, at least for a few weeks to few months. To do this, the spinal cord on the side opposite the pain is sectioned almost entirely through its antero-lateral quadrant, which interrupts antero-lateral sensory pathway.(17)A cordotomy, however is not always successful in relieving pain for two reasons.

1. Many pain fibers from upper part of body do not cross to opposite side of spinal cord, until they have reached the brain, so that cordotomy does not transect these fibers.

2. Pain frequently returns several months later partly as a result of sensitization of other pain pathways that are normally too weak to be effectual. This new pain is often even more painful than the original pain. ${ }^{(18)}$

Another experimental operative procedure to relieve pain has been to cauterize specific pain areas in intralaminar nuclei in the thalamus, which often relieves the suffering type of pain while leaving intact one's appreciation of acute pain an important protective mechanism.

Surgical interruption of pain pathways The degree to which a person reacts to pain varies tremendously. This results partly from a capability of brain itself to suppress input of pain signals to the nervous system by activating a pain control system, called an analgesia system.

The analgesia system. It consist of three major components:

1. The periaqueductal gray and periventricular areas of mesencephalon and upper pons surrounding the aqueduct of sylvius and portions of third and fourth ventricles constitute this System. Neurons from these areas send their signals to spinal cord. ${ }^{(19)}$

2. Raphemagnus nucleus, thin midline nucleus located in lower pons, and upper medulla and nucleus reticularis para gigantocellularis located laterally in the medulla. From these nuclei signals are transmitted down the dorsolateral columns in spinal cord. ${ }^{(20)}$

3. A pain inhibitory complex located in dorsal horns of spinal cord. At this point the analgesia signals can block pain before it is relayed to brain. ${ }^{(21)}$

Several transmitter substances are involved in analgesia system, especially involved are enkephalins and serotonin. Enkephalin is, believed to cause both presynaptic inhibition and post synaptic inhibition of incoming type $\mathrm{C}$ and type $\mathrm{A}$ delta (Ad) pain fibers where they synapse in the dorsal horns. It probably achieves the presynaptic inhibition by blocking calcium channels in the membranes of nerve terminals. Because it is calcium that cause release of transmitter at synapse, such calcium blockage would result in presynaptic inhibition. The analgesia often lasts for many minutes or even hours. ${ }^{(22)}$

\section{Brain Opiate System}

Consist of endorphins and enkephalins.

Pro-opiomelanocortin, pro-enkephalin, prodynorphin beta-endorpbin. Break down products 
of these molecules met-enkephalin, leuenkephalin and dynorphin.

Inhibition of pain signals transmission by tactile sensory signals

The stimulation of large type $A B$ sensory fibers from the peripheral tactile receptors can depress the transmission of pain signals. This effect presumably results from local laterial inhibition of spinal cord. ${ }^{(23)}$

\section{Gate control theory of pain suppression:}

Ronald Melzack and Patric Wall (1965) proposed that from injured site impulses are carried to transmitter cell (T) in spinal cord by both A delta (Ad) and C fibers. Simultaneously both these fibers also send impulses to inhibitory inter neurons which in turn send inhibitory impulses to T cells. ${ }^{(24)}$

The impulses coming from A delta (Ad) fibers stimulates both inhibitory neuron and $\mathrm{T}$ cells whereas impulses coming in $\mathrm{C}$ fibers inhibit only the inter neurons but stimulate $\mathrm{T}$ cells. According to this theory $\mathrm{T}$ cell is the gate for transmission of pain sensation to higher centers. The stimulation of small fibers opens the gate and that of large fibers close the gate. ${ }^{(25)}$

When $\mathrm{C}$ fiber is stimulated it causes inhibition of inhibition by $\mathrm{I}$ cell on $\mathrm{T}$ cell. Therefore it disinhibits the inhibition and opens the gate for transmission of pain from $\mathrm{T}$ cells. When A delta (A $\delta)$ fiber is stimulated it stimulates I cell therefore exerts inhibition on $\mathrm{T}$ cells hence gate for pain is closed. This theory tries to explain why such simple maneuvers as rubbing skin near painfull areas is many a times effective in relieving pain and also pain relief by acupuncture.

Referred Pain: Often a person feels pain in a part of his or her body that is considerably remote from tissue causing pain. This pain is called "referred pain". The pain usually is initiated in one of the visceral organs and referred to an area on the body surface. The pain may be referred to an area by body not exactly coincident with the location of viscus producing the pain. Knowledge of different type of referred pain is important in clinical diagnoses because many visceral ailments cause no other clinical sign except referred pain. ${ }^{(26)}$

The branches of visceral pain fibers are shown to synapse in the spinal cord on same second order neurons $(1 \& 2)$ that receive pain signals from skin. When visceral pain fibers are stimulated pain signals from viscera are then conducted through at least some of the same neurons that conduct pain signals from skin and the person has the feeling that sensation originated in skin itself. ${ }^{(27)}$

Visceral Pain: Viscera have sensory receptors for no other modalities of sensation besides pain. Also visceral pain differs from surface pain in several important aspects. One of the most important differences between surface pain and visceral pain is that localized types of damage to viscera seldom cause severe pain. For instance, a surgeon can cut the gut entirely in two in a patient who is awake without causing significant pain. Conversely any stimulus that causes diffuse stimulation of pain nerve ending throughout a viscus causes pain that can be severe. For instance ischaemia caused by occluding the blood supply to a large area of gut stimulates many diffuse pain fibers at the same time and can result in extreme pain. ${ }^{(28)}$

\section{Causes of True Visceral Pain}

1. Ischemia: Ischemia causes visceral pain in same way that it does in other tissues, presumably because of formation of acidic metabolic end products or tissue degenerative products such as bradykinin proteolytic enzymes or others that stimulate the pain nerve endings.

\section{Painful Conditions}

- Hyperalgesia: Increased pain from a stimulus that normally provokes pain.

- Nuropathic pain: Pain caused by a lesion or disease of the somatosensory nervous system.

- Allodynia: Pain due to stimulus that does 
not normally produce pain.

- Sensitisation: Increased responsiveness of nociceptive neurons to their normal input and recruitment of a response to a normally subthreshold stimulus.

2. Chemical stimuli: On occasion damaging substances leak from GIT into peritoneal cavity, for instance proteolytic acidic gastric juice often leaks through a ruptured gastric or duodenal ulcer, this juice causes wide spread digestion of visceral peritoneum thus stimulating broad areas of pain fibers. The pain is excruciatingly severe.

3. Spasm of hollow viscus: Pain is intermittently occurring results from rhythmical contraction once every few minutes.

4. Over distention of hollow viscus: Extreme overfilling of hollow viscus can result in pain because of overstretch of tissue. ${ }^{(29)}$

\section{Perietal pain caused by visceral damage:}

When disease affects a viscus, the disease process often spreads to parietal peritoneum, pleura or pericardium. These parietal surfaces like skin are supplied extensive pain innervation from peripheral spinal nerves. The pain is frequently sharp.

\section{Localization of referred pain transmitted via the visceral pathway:}

When visceral pain is referred to surface of body, the person generally localizes it in dermatomal segment from which visceral organ originated in embryo, not necessarily where visceral organ now lies. For instance, the heart originates in neck and upper thorax so that hearts visceral pain fibers passes upward along the sympathetic nerves and enter spinal cord between segments C3 and T5. Pain from heart is referred to side of neck over shoulder, over pectoral muscles, down the arms and into substernal area of upper chest.

The stomach originated approximately from seventh to ninth thoracic segments of embryo. Therefore, the stomach pain is referred to anterior epigastrium above umbilicus. ${ }^{(30)}$

\section{Discussion}

This article gives a broad overview of the physiology of pain. It explains pain as a complex experience involving both physical and psychological adaptations. The normal pain pathways are described in some detail in a systematic fashion from nociceptor to central nervous system and back to periphery. ${ }^{(1,2,3)}$ It concludes with an explanation of some of the mechanisms involved with pain transmission An overview of pain pathways is presented, beginning in the periphery and progressing centrally, and the ascending and descending pathways are described in detail. ${ }^{(4)}$ The nociceptive pathway, consisting of the classic three-neuron chain, is now understood to be a dual system at each level, and the sensation of pain is thought to arrive in the central nervous system with the discriminative component of pain ("first pain") carried separately from the affectivemotivational component of pain ("second pain"). In addition to spinal control mechanisms of nociceptive transmission, descending pathways that originate in three major areas - the cortex, thalamus, and brain stem - can modify functions at the spinal level. ${ }^{(16,32)}$ At every level of the nervous system, a close relationship prevails between somatic pain pathways and visceral pathways. This relationship likely accounts for the transmission of visceral pain and also for autonomic responses to somatic pain and somatic responses to visceral pain. One of the most important difference between surface pain and visceral pain is that localized types of damage to viscera seldom cause severe pain. For instance, a surgeon can cut the gut entirely in two in a patient who is awake without causing significant pain. ${ }^{(33)}$ Summary of the mechanistic approaches to the treatment of pain Based on one's knowledge of the neurophysiology of pain and the specific mechanisms involved, therapeutic strategies may be selected. Nociceptive pain arising in the periphery may be treated by reduction of inflammation (NSAID), blocking the activity of 
the nerve fibers (ion channels blockers), or by acting on the C-fiber receptors by using an agent such as capsaicin ${ }^{(4)}$. If there is reason to suspect hyperactivity of spinal neurons following a sensitization of the CNS (allodynia, hyperalgesia),as explained in our study then anticonvulsant or antiarrhythmic agents are used to reduce neuronal hyperactivity. NMDA antagonists could also be used to reverse this hyperactivity. It is also possible that the prophylactic use of these agents, such as during surgery, may prevent chronic pain. ${ }^{(33,34)}$ If the descending inhibitory mechanisms are implicated, the use of serotoninergic and noradrenergic agonists, as in the antidepressants, may help to recruit and modulate these systems. When disease affects a viscus, the disease process often spreads to parietal peritoneum, pleura or pericardium. These parietal surfaces like skin are supplied extensive pain innervation from peripheral spinal nerves. ${ }^{(35)}$ The pain is frequently sharp. Finally, antidepressant medications, opioids, and the anticonvulsant drugs would also have an effect on the higher centers influencing the motivational aspect of pain. Cognitive manipulation can also play a role in pain modulation. Harnessing these mechanisms from higher cerebral centers by use of distraction, relaxation, suggestion, and positive support will facilitate pain management. ${ }^{(36)}$ These pharmacologic and nonpharmacologic examples, based on the neurophysiologic characteristics of the pain, demonstrate that a better understanding of the mechanisms of pain generation will influence therapeutic approaches and facilitate treatments. Summary. This article has described the complexity of the pain phenomenon and explained mechanisms involved in the development and maintenance of pain conditions. This knowledge is a strong foundation on which to develop a therapeutic guide for the treatment of pain. ${ }^{(37)}$ Although there is commonality in the nociceptive pathways of our patients, each individual will respond differently and specifically to pain as a result of genetic and environmental background. This variability in perception and response to pain may lead to physician bias or even misinterpretation of an individual patient's symptoms. ${ }^{(38)}$ Keeping in mind the heterogeneity of the pain response and the unique characteristics of an individual patient will lead to better patient care. $^{(39)}$ Understanding the neurophysiologic mechanisms underlying the development and maintenance of pain will help focus treatments more efficiently toward the specific abnormality causing pain. ${ }^{(40)}$ The knowledge of the science of pain has provided an opportunity to address pain from a mechanistic approach, with the objective of reinforcing inhibitory mechanisms or reducing the hyperactivity of the nociceptive response. ${ }^{(41)}$ Functional neurogenic pain is a subcategory of neurogenic pain occurring in the absence of a defined anatomic lesion within the nervous system, ${ }^{(42)}$ but rather representing a dysfunction of pain modulation mechanisms. This may occur as a result of central activation of endogenous excitatory systems that will amplify the nociceptive signal or by a dysfunction of endogenous inhibitory mechanisms. ${ }^{(43)}$ An example of central hyperactivity is the thalamic syndrome following a lesion of thalamic nuclei as a result of a cerebral event. This lesion will produce hyperactivity of thalamic neurons that are normally inhibited by a complex interneuron network. ${ }^{(44)}$ A small lesion within the thalamus may result in intense pain over a large body area, frequently involving almost half of the body. In contrast, another pain syndrome, namely FM, may be at least partly explained by a deficit of descending endogenous pain inhibitory 304 MARCHAND mechanisms ${ }^{(45)}$. In this condition the hyperalgesia is related to lack of inhibition, rather than just hyperactivity of the nociceptive neurons. ${ }^{(46)}$ Therefore, strategies for the treatment of functional neurogenic pain will be either focused toward reduction of nociceptive hyperactivity or activation of endogenous inhibition. Anticonvulsants will reduce sensory input by effect on ion channels, whereas antidepressant medications will augment inhibition by effect on serotonin and 
noradrenergic system.

\section{Conclusion}

The neurobiology of pain is continuously being explored and the novel therapeutic targets for pain relief are being tested. The multiple complex circuitries of the pain pathway, with central and peripheral modulation of the perception, make it a very complex sensation with sensory, cognitive and emotional components associated with it. The variety of neurochemicals and receptors involved in the perception of pain has led to the search for many targets of pain relief. By understanding the pathways of pain and the transmitters involved, prevention and treatment of pain will be improved Novel targets are being studied to counteract pain syndromes which are resistant to current treatment modalities. Site-specific and selective agents are receiving a lot of attention with the hope for high efficacy and minimal side effects.

\section{References}

1. Guyton $4^{\text {th }}$ edition 2020 textbook of medical physiology Mc Graw Hill Pub

2. Longo Dam $20^{\text {th }}$ edition 2018 Harrisons principal of internal medicine volume $\mathrm{Mc}$ Graw Hill pub

3. Bear Mark $4^{\text {th }}$ edition 2016 Neuroscience exploring the brain Lippincot

4. Hall john $3^{\text {rd }}$ edition 2020 Guyton and Hall textbook of physiology Read Elsevier

5. Siegal Allan $4^{\text {th }}$ edition 2018essential of Neuroscience wolters kluwer

6. krebs $2^{\text {nd }}$ edition 2017 wolters kluwer

7. Melnikova I. Pain market. Nature Reviews Drug Discovery2010; 9: 589-90.

8. Rao PPN, Mohamed T. Current and emerging at-site pain medications: a review. Journal of Pain Research 2011; 4:279-86.

9. Millan MJ. The induction of pain, an integrative review.Progress in Neurobiology 1999; 57: 1-164.

10. Willis WD, Westlund KN. Neuroanatomy of the pain system and of the pathways that modulate pain. Journal of Clinical Neurophysiology 1997; 14: 2-31.

11. Vranken JH. Elucidation of Pathophysiology and Treatment of Neuropathic Pain. Central Nervous System

12. Borsook D, Becerra L. How close are we in utilizing functional neuroimaging in routine clinical diagnosis of neuropathic pain? Current Pain Headache Reports 2011; 15: 223-29.

13. Brooks J, Tracey I. From nociception to pain perception, imaging the spinal and supraspinal pathways. Journal of Anatomy 2005; 207:19-33.

14. Price DD. Central neural mechanisms that interrelate sensory and affective dimensions of pain. Molecular Interventions 2002; 2: 392-402.

15. Aggugia M. Neurophysiology of Pain (review). Neurological Sciences 2003; 24: S57-60.

16. Millan MJ. The induction of pain: an integrative review. Prog Neurobiol 1999;57(1):1-164.

17. Traub RJ. Spinal modulation of the induction of central sensitization. Brain Res 1997; 778(1):34-42.

18. Reynolds DV. Surgery in the rat during electrical analgesia. Science 1969; 164(878):444-5. THE PHYSIOLOGY OF PAIN MECHANISMS 307

19. Fields HL, Basbaum AI. Anatomy and physiology of a descending pain control system. In: Bonica BJ, editor. Advances in pain and research and therapy. New York: Raven Press; 1979. p. 427-40.

20. Le Bars D, Dickenson AH, Besson JM. Diffuse noxious inhibitory controls (DNIC). II.Lack of effect on nonconvergent neurones, supraspinal involvement and theoretical implications. Pain 1979;6(3):305-27

21. Costigan M, Scholz J, Woolf CJ. Neuropathic Pain: A Maladaptive Response of the Nervous System to 
Damage. Annual Review of Neuroscience 2009; 32: 1-32.

22. Woolf CJ, Shortland P, Reynolds M, Ridings J, Doubell T, Coggeshall RE. Reorganization of central terminals of myelinated primary afferents in the rat dorsal horn following peripheral axotomy. Journal of Comparative Neurology 1995; 360: 121-34.

23. Bennett GJ. NMDA-Receptor Antagonists: Evolving Role in Analgesia, Update on the Neurophysiology of Pain Transmission and Modulation: Focus on the NMDAReceptor. Journal of Pain and Symptom Management 2000; 19: S2-6 (Proceedings Supplement ).

24. Woolf CJ. Central sensitization, implications for the diagnosis and treatment of pain. Pain 2011; 152: S2-S15.

25. Coull JA, Beggs S, Boudreau D, Boivin D, Tsuda M, Inoue K, Gravel C, Salter MW, De Koninck, Y. BDNF from microglia causes the shift in neuronal anion gradient underlying neuropathic pain. Nature 2005; 438: 1017-21.

26. Gwak YS, Hulsebosch CE. GABA and central neuropathic pain following spinal cord injury. Neuropharmacology 2011; 60: 799-808.

27. Budai D, Harasawa I, Fields HL. Midbrain periaq-ueductal gray (PAG) inhibits nociceptive inputs to sacral dorsal horn nociceptive neurons through alpha2adrenergic receptors. Journal of Neurophysiology 1998; 80: 2244-54.

28. Gassner M, Ruscheweyh R, Sandkuhler J. Direct excitation of spinal GABAergic interneurons by noradrenalin. Pain 2009; 145: 204-10.

29. Doly S, Fischer J, Brisorgueil MJ, Verge D, Con-rath M. Preand postsynaptic localization of the 5-HT7 receptor in rat dorsal spinal cord: immunocytochemical evidence. Journal of Comparative Neurology 2005 ; 490: 256-69.
30. Bardin L. The complex role of serotonin and 5-HT receptors in chronic pain. Behavioral Pharmacology 2011; 22: 390404.

31. Díaz JL, Zamanillo D, Corbera J, Baeyens JM, Maldonado R,Pericàs MA, Vela JM, Torrens A. Selective sigma-1 (sigma1) receptor antagonists: emerging target for the treatment of neuropathic pain. Central Nervous System Agents in Medicinal Chemistry 2009; 9: 172-83.

32. Ossipov MH, Gregory OD, Porreca F. Central modulation of pain. The journal of clinical investigation 2010; 11: 3779-89.

33. Guindon J, Beaulieu P, Hohmann AG. Pharmacology of thecannabinoid system. In: Beaulieu P, Lussier D, Porreca F,

34. Dickenson AH, editors. Pharmacology of pain. Seattle: IASP Press, 2010; 66] Granot M, Granovsky Y, Sprecher E, et al. Contact heat-evoked temporal summation: tonic versus repetitive-phasic stimulation. Pain 2006;122(3):295-305. 33 Woolf CJ. Windup and central sensitization are not equivalent. Pain 1996;66(2-3): 105-8.

35. Price DD, Dubner R. Mechanisms of first and second pain in the peripheral and central nervous systems. J Invest Dermatol 1977;69(1):167-71. 306 MARCHAND

36. Vierck CJ Jr, Cannon RL, Fry G, et al. Characteristics of temporal summation of second pain sensations elicited by brief contact of glabrous skin by a preheated thermode. J Neurophysiol 1997;78(2): 992-1002.

37. Li J, Simone DA, Larson AA. Windup leads to characteristics of central sensitization. Pain 1999;79(1):75-82.

38. Eide PK. Wind-up and the NMDA receptor complex from a clinical perspective. Eur J Pain 2000;4(1):5-15.

39. Woolf CJ, Thompson SW. The induction and maintenance of central sensitization is dependent on N-methyl-D-aspartic acid receptor activation; implications for the 
treatment of postinjury pain hypersensitivity states. Pain 1991; 44(3):293-9.

40. Marchand S, Arsenault P. Spatial summation for pain perception: interaction of inhibitory and excitatory mechanisms. Pain 2002;95(3):201-6.

41. Staud R, Vierck CJ, Cannon RL, et al. Abnormal sensitization and temporal summation of second pain (wind-up) in patients with fibromyalgia syndrome. Pain 2001;91(1-2): 165-75.

42. Julien N, Goffaux P, Arsenault P, et al. Widespread pain in fibromyalgia is related to a deficit of endogenous pain inhibition. Pain 2005;114(1-2):295-302.

43. Willis WD. Nociceptive pathways: anatomy and physiology of nociceptive ascending pathways. Philos Trans R Soc Lond B Biol Sci 1985;308(1136):253-70.

44. Palecek J, Paleckova V, Willis WD. Fos expression in spinothalamic and postsynaptic dorsal column neurons following noxious visceral and cutaneous stimuli. Pain 2003;104(1-2): 249-57.

45. Palecek J, Willis WD. The dorsal column pathway facilitates visceromotor responses to colorectal distention after colon inflammation in rats. Pain 2003; 104(3):501-7.

46. Willis WD, Kenshalo DR Jr, Leonard RB. The cells of origin of the primate spinothalamic tract. J Comp Neurol 1979;188(4):543-74.

47. Lenz FA, Gracely RH, Romanoski AJ, et al. Stimulation in the human somatosensory thalamus can reproduce both the affective and sensory dimensions of previously experienced pain. Nat Med 1995;1(9):910-3.
48. Coghill RC, Talbot JD, Evans AC, et al. Distributed processing of pain and vibration by the human brain. J Neurosci 1994;14(7):4095-108.

49. Talbot JD, Marrett S, Evans AC, et al. Multiple representations of pain in human cerebral cortex. Science 1991;251 (4999):1355-8.

50. Basbaum AI, Fields HL. Endogenous pain control mechanisms: review and hypothesis. Ann Neurol 1978;4(5):451-62. 